\title{
Nutrition in children and adolescents in Europe: what is the scientific basis? Introduction
}

\author{
B. Koletzko, V. de la Guéronnière, A. M. Toschke and R. von Kries
}

\section{Background}

The aims of the present report are to provide an introductory overview of the aims, concepts and elements of the project reviewing the nutritional needs of children and adolescents in Europe, and to raise some general questions on the topic addressed.

The International Life Sciences Institute (ILSI) Europe (http://europe.ilsi.org) invited renowned experts in the field from across Europe to review current scientific information related to nutrition in healthy children and adolescents in Europe, and to identify current and future trends on children's nutritional needs. This ILSI initiative was prompted by the observations that most current information regarding nutritional needs in the paediatric age group is on children under the age of 2 years, and that a number of controversial conclusions had been drawn on the nutritional needs and priorities of older children and adolescents. Therefore, the participants of this project tried to review available scientific information related to the nutrition of healthy children and adolescents in Europe. It is expected that these considerations will aid in establishing a broader consensus on dietary guidance for a healthy childhood and adolescence, in deriving sound conclusions on the nutritional status of this part of the population, and in developing improved strategies to meet their nutritional needs.

From the spring of 2001 until the summer of 2003, two expert groups collected and critically reviewed available data on two specific issues. One group, chaired by Dr Ann Prentice (Elsie Widdowson Laboratory, Cambridge, UK), performed the enormous task of compiling the existing dietary reference values on energy and nutrient intakes for childhood populations in Europe (Prentice et al. 2004). For each nutrient the members of the expert group assessed the availability of data, the scientific evidence for the nutrient recommendation, and possible explanations for the differences observed. In order to fulfil this task, the group had to come to agreement with respect to a number of technical aspects, such as standard age groups, definition of nutrient recommendations, methodological issues, conversion factors and others. The task of the second expert group, chaired by Dr Janet Lambert (Masterfoods, UK), was not any less demanding. This group collected and reviewed available data on dietary intakes and nutritional status in populations of children and adolescents in Europe, compiled the data into tables and tried to evaluate the information available (Lambert et al. 2004). The group also assessed the methodological approaches used to obtain such data and critically discussed the lack of reliability and comparability of much of the data, along with important intrinsic limitations such as the variety of different methodological approaches and databases for food composition that are used, subjects misreporting on diet intake, and others.

The extremely valuable reports of these two expert groups are published in this issue of British Journal of Nutrition, after having been reviewed and commented on by some 50 leading experts in the field who attended a scientific workshop organised by ILSI Europe and held in Rome in May 2003. Participants of the workshop highlighted discrepancies in dietary recommendations and reported dietary intakes between countries, explored possible explanations for these differences and their significance, highlighted methodological issues, identified specific areas where data are conflicting or lacking and where further research is needed, discussed the scientific background for definitions and uses of dietary recommendations, explored the relevance of an approach based primarily on physiological functions and health promotion of children and adolescents rather than on nutrients, and discussed potential future steps to be performed. The issues raised at the workshop have been considered and addressed as far as possible in the summaries published in this issue (Lambert et al. 2004; Prentice et al. 2004).

In addition, working groups were held at this workshop that focused on areas not commonly approached, including food habits and cultural traditions, food components with newly recognised physiological roles, fluid needs, and nutrient handling and bioavailability. Summaries of the outcomes of these working groups are also published in the present issue.

\section{General aspects in defining population reference intakes} for children and adolescents

A variety of different aspects must be considered if one aims at best fulfilling the nutritional needs of populations of children and adolescents. Obviously, a primary goal is 
to meet the metabolic requirements for water, energy and nutrients. A refined definition of nutrient requirements has recently been proposed by the Committee on Nutrition of the European Society for Paediatric Gastroenterology, Hepatology and Nutrition:

'The ideal definition of a physiological requirement is the amount and chemical form of a nutrient that is needed systematically to maintain normal health and development

without disturbance of the metabolism of any other nutrient. The corresponding dietary requirement would be the intake sufficient to meet the physiological requirement:

Ideally this should be achieved without extreme homeostatic processes and excessive depletion or surplus in bodily depots.'

(Aggett et al. 1997)

Some specific aspects need to be taken into consideration when trying to define nutrient requirements, or reference intakes, for populations of children and adolescents. In contrast to adults, the nutrient supply for children and adolescents needs to cover not only the requirements for maintenance metabolism, obligate losses and physical activity. In addition, children have high and specific substrate needs for growth, which are particularly large during the phases of rapid growth in infancy, during the pre-school growth spurt and the pubertal growth spurt (Koletzko et al. 1998). In contrast to their high metabolic demands, children tend to have a more limited ability to compensate for unbalanced nutrient supplies than do adults by homeostatic adaptation, primarily because of their smaller body stores of nutrients. Moreover, the metabolic handling of various substrates differs with age and body size. Of further importance is the longer life expectancy of children, for whom there is thus a higher probability that the quantity and quality of nutrition will have relevant long-term effects on later well-being and health outcomes such as cardiovascular health, particularly since nutrition during the time of organ growth and differentiation in childhood has been shown to induce permanent imprinting effects on organ structure and function (Koletzko et al. 1998).

In contrast to the great relevance of the issue, the scientific database on which conclusions on nutrient requirements for children might be based is rather limited, as exemplified by an electronic literature search performed on 25 August 2003 by one of the authors (B. K.) in PubMed, National Library of Medicine (http://www.ncbi. nlm.nih.gov/entrez/query.fcgi). The search term 'nutrient requirement' limited to 'clinical trial' and 'human' revealed 176 hits for adults and fifty-three for newborn infants, but only twenty-one for pre-school children aged 2-5 years, twenty-nine for children aged 6-12 years, and forty-five for children and adolescents aged 13-18 years. Since the database for children and adolescents is limited and often inadequate as a basis for deriving evidence-based population reference intakes for different paediatric age groups, estimates of adequate nutrient intakes for children and adolescents are often extrapolated from values established for adults and for young infants, usually based on average data for body weight or body surface area (Scientific Committee on Food, 1993; Aggett et al. 1997).
A similar approach of linear extrapolation is also frequently used to derive upper safe levels of nutrient intake, i.e. maximal nutrient intake levels at which untoward effects are unlikely, because again in most cases there is a far too limited scientific basis for a direct, evidence-based derivation of upper safe levels of nutrient intake for the different paediatric age groups. However, there is no reason to assume that such linear extrapolations would result in adequate levels of reference intakes or of upper safe levels of nutrient intakes. Major concerns on these shortcomings were recently emphasised by the Scientific Committee on Food of the European Community with regard to upper levels of intake:

'The Committee recognises limitations in the methods available and in the approach it has used to extrapolate tolerable upper intake levels (UL) of nutrients from those established for adult populations to children, based solely either on body weight or on body surface area. For some nutrients, the Committee concluded that an extrapolation on the basis of body weight or body surface area would yield UL for children that were incompatible with known nutrient requirements and refrained from recommending UL for children. Physiological differences between adults and young children, especially at a young age, are both quantitative and qualitative in nature. Existing differences in substrate absorption, metabolism, deposition in tissues during growth, and renal or other excretion that may affect UL of nutrient intakes are not always closely related to

body size. The Committee recommends this issue be reviewed in order to establish whether further refinements in the approach or further research are needed.'

(Scientific Committee on Food, 2003a)

It is evident that further systematic scientific research is urgently required to establish adequate data on the physiological nutrient requirements of children and adolescents (Aggett et al. 1997). The opportunity is there, because methodological progress has made less invasive or noninvasive approaches available that allow ethical investigations on a number of these issues in healthy children; for example, stable isotope breath tests for the estimation of amino acid requirements (Pencharz \& Ball, 2003). Therefore, it would be feasible today to narrow many of the existing gaps in knowledge in this respect, if such research were given sufficient priority by both academic institutions and funding agencies.

Even though many of these data are still outstanding, numerous expert bodies have been asked to provide estimations of adequate nutrient provisions for populations of children and adolescents and have come up with estimates of appropriate intakes (Prentice et al. 2004). The values published for reference intakes of nutrients by the many different committees vary quite considerably, which appears to result partly from the lack of precise data on which to base them, and hence the need for some degree of subjective judgement in obtaining reference values, and partly from major differences in underlying concepts as to how one should arrive at reference values (Prentice et al. 2004). Also, the terminology used by various bodies differs: for example, for similar concepts the terms Population Reference Intakes (PRI; Scientific Committee on Food, 
1993), Reference Values for Nutrient Intakes (RNI German Nutrition Society, 2003) and Dietary Reference Intakes (DRI; Institute of Medicine, 2003) are used in parallel, which has caused added confusion. The uses of such reference values are varied and include the comparison with and assessment of results of dietary surveys and food statistics, the provision of guidance on appropriate dietary composition or meal provision, and making policy decisions on supplementation strategies. However, inappropriate uses due to misunderstandings on the meaning of reference values and the underlying assumptions and statistical concepts are common. For example, many health professionals assume that reference intake values would provide a reliable basis for the specific advice they give on the feeding of individual children.

Reference intake values are also used as the basis for defining values for the labelling of nutrient content of foods, i.e. for deriving reference labelling values. Although it had previously been considered that estimated average requirements of populations might serve as the basis for establishing labelling (Scientific Committee on Food, 1993), the general consensus now is that population reference intake values, i.e. intakes expected to meet the nutrient needs of most if not all individuals within a population, are the appropriate basis for defining reference labelling values (Scientific Committee on Food, 2003b).

Given the multiple and widespread applications of population reference intake values, the current situation with not only differences in values but also major differences in underlying concepts and definitions between national recommendations is unfortunate, particularly if one considers that European nations are now rapidly growing closer with marked movement of people, information and goods across Europe. Therefore, steps towards achieving harmonisation appear timely. A concerted action of individual scientists, and of scientific societies and governmental agencies, from all parts of Europe that are involved in the scientific basis for and in the actual establishment of reference intake values could be helpful. Such a concerted action could try to move towards a consensus on concepts and approaches, definitions, age groups and other technicalities for the development of dietary reference values for children and adolescents, and on approaches for food-based dietary guidelines in children and adolescents, which might be of tremendous value in achieving a stepwise harmonisation of such recommendations. It should also be tried to harmonise on methodologies used for assessment of dietary intake and nutritional status in children and adolescents, to move towards arriving at better comparable information across Europe.

\section{Additional aspects relevant in meeting nutritional needs of children and adolescents}

Aspects other than basic nutrient requirements must be considered in approaching the nutritional needs of the paediatric age group. The overall quality and safety of foods, of food handling and of packaging is of major importance for meeting nutritional needs, but these aspects lie outside the scope of the project addressed here. It needs to be considered that eating not only provides a supply of nutrients, but also many pleasures as well as serving a variety of social and cultural functions.

The relevance of the nutrient supply itself is not only determined by the need to cover requirements that avoid overt deficiency. Scientific evidence accumulates that intakes of nutrients over and above levels needed to meet basic nutrient requirements, as estimated by population reference intakes, may provide important additional benefits for the health and well-being of children and adolescents in some instances (Koletzko et al. 1998). For example, total homocysteine levels in plasma, which are considered a marker for thrombotic and cardiovascular risks (Nygard et al. 1997; Rimm et al. 1998), were found to correlate inversely with plasma levels of vitamin $\mathrm{B}_{12}$ and folate in young populations consuming intakes of these $\mathrm{B}$ vitamins that generally met estimated requirements (Rauh et al. 2001), indicating the potential for health benefits at higher intake levels. Moreover, non-nutrient contents in the diet may induce relevant beneficial effects for health, well-being, growth and development, for example the provision of adequate amounts of certain non-digestible carbohydrates (Koletzko et al. 1998; Aggett et al. 2003). On the other hand, the composition of foods consumed and eating habits may increase the probability for serious health risks, such as overweight, obesity, type II diabetes and metabolic syndrome, and cardiovascular diseases. Particular attention is given to overweight and obesity in children and adolescents owing to their high and rapidly rising prevalence across Europe.

\section{Meeting nutritional needs of children and adolescents: prevention of obesity}

The prevalence of overweight and obesity in children and adolescents has risen greatly world-wide during the past two decades, with a combined prevalence of childhood overweight and obesity reaching $20 \%$ in many European countries (Ebbeling et al. 2002; Koletzko et al. 2002; see Fig. 1). This most worrying development is obviously the result of adverse environmental and life-style factors. Although genetic disposition and early metabolic programming modulate the risk for development of obesity (von Kries et al. 1999; O'Rahilly et al. 2003), the prerequisite for becoming obese is an imbalance between energy expenditure, modulated primarily by physical activity, and energy intake from foods and drinks (Joint WHO/ FAO Expert Consultation, 2003). Physical activity levels in European children have tended to decrease, with an increase of sedentary behaviour such as television watching, where frequent television viewing is associated with higher obesity prevalence (Kalies et al. 2001).

At the same time, marked changes in eating culture and behaviour have occurred at an extremely rapid pace (Joint WHO/FAO Expert Consultation, 2003). The wide availability and frequent consumption of energy-dense foods and drinks, such as foods with high fat content, have been associated with the increase in obesity prevalence in children (Koletzko et al. 2002), and some experts have considered possible benefits of banning specific food products or imposing fiscal or other restrictions. However, it is not 
(a)

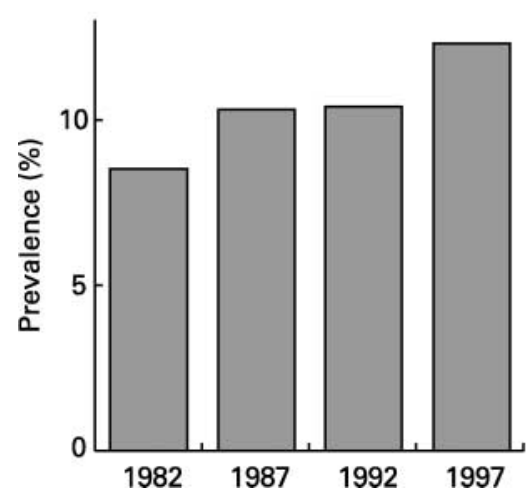

(b)

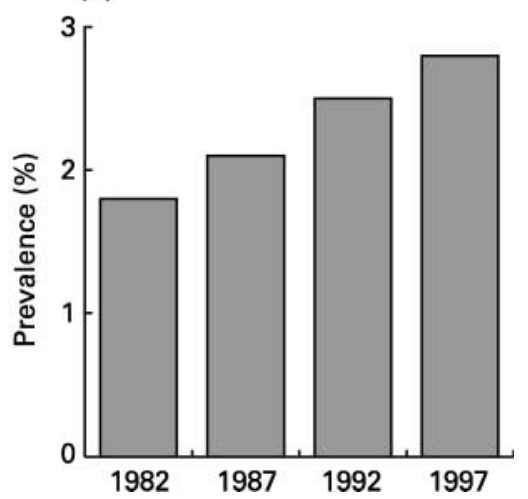

Fig. 1. Rapidly increasing prevalence of (a) overweight (BMI $>90$ th percentile) and (b) obesity (BMI $>97$ th percentile) among children entering primary school in Bavaria (Germany) between 1982 and 1997 . Overweight prevalence rises by $0.3 \%$ annually $(P=0.001)$, obesity prevalence by $0 \cdot 1 \%$ annually $(P=0.004)$. (Drawn from data of Kalies et al. 2002.)

clear whether such prohibitive measures would be effective in combating childhood obesity. Therefore, we assessed the frequency of consumption of food items that are often considered to be associated with the development of overweight and obesity with self-administered questionnaires. These questionnaires were given out at the obligatory health examination held in Bavaria prior to school entry, in the city of Ingolstadt with a high population density (847 inhabitants $/ \mathrm{km}^{2}$ ), in the outskirts of the city of Augsburg (214 inhabitants $/ \mathrm{km}^{2}$ ) and in four rural areas (Miesbach, Günzburg, Kitzingen and areas surrounding

(a)

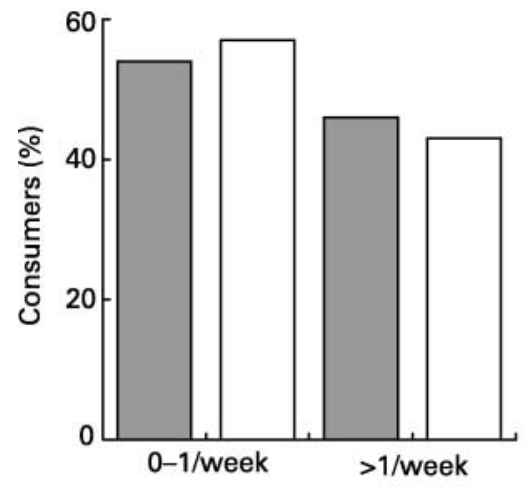

(c)

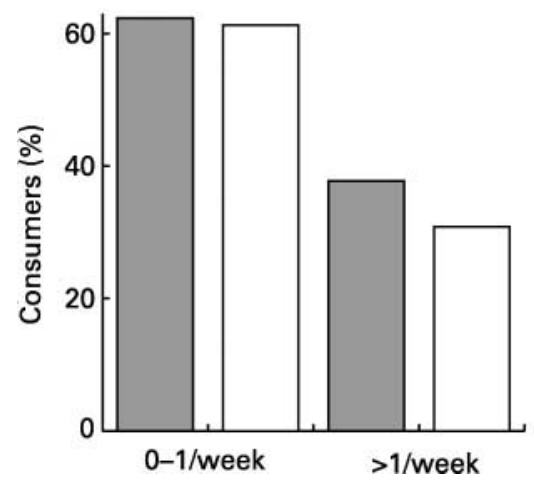

Regensburg; all with $<200$ inhabitants $/ \mathrm{km}^{2}$ ). We received and evaluated informative questionnaires for 6862 Bavarian children aged 5 and 6 years, which had been completed mostly by the mother only $(81 \%)$ or by both parents $(16 \%)$. The analysis of the data revealed that children with overweight, defined as BMI >90th percentile, did not show a more frequent consumption of chocolate, sugared drinks, cake, and chips, peanuts and cookies (Fig. 2) than children with normal weight. Thus, the development of overweight appears to be caused by far more complex factors than only the simple frequency of

(b)

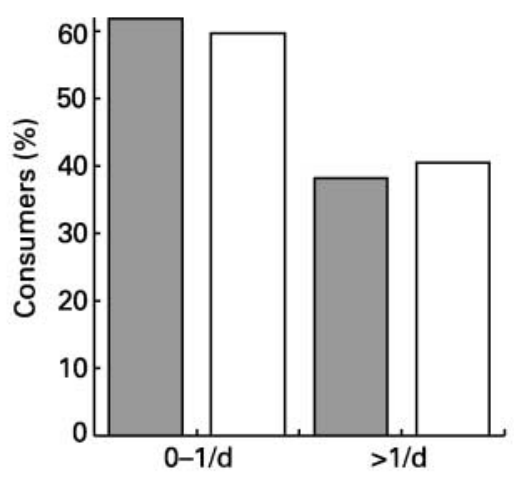

(d)

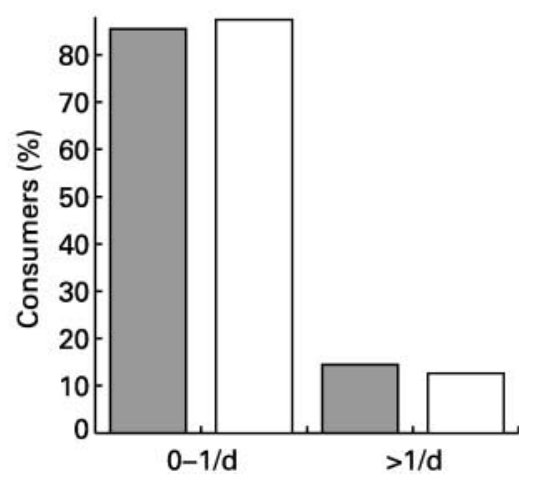

Fig. 2. We assessed the frequency of consumption of food items often considered to be associated with the development of overweight and obesity by self-administered questionnaires at the obligatory health examination prior to school entry in 6862 Bavarian children aged 5 and 6 years from three rural regions. Overweight children (BMI > 90th percentile; $\square$ ) did not show more frequent consumption of (a) chocolate, (b) sugared drinks, (c) cake and (d) chips, peanuts and cookies than normal-weight children ( $\square$ ) (corrected for missing values). 
consumption of single food items, and regulatory restrictions on selected food items may not be a suitable tool to combat the obesity epidemic.

However, the eating habits of childhood populations are presently undergoing marked changes. Eating embedded in traditional social contexts and cultural traditions, such as family meals at regular times with home-made foods prepared according to regional customs, is rapidly being replaced by individual consumption of prepared foods, for example by snacking on the go and in the street, on the bus, or in front of the television. In the USA, the proportion of household expenses spent on meals prepared outside the home, including foods consumed in restaurants and food outlets as well as take-out foods, was $28 \%$ of households' food expenditure in 1993 and had almost doubled by 2002 (C Williams, unpublished results). This shift away from meals to snacks, and from at-home consumption to away-from-home consumption, has been associated with an increase in total energy intake over the past twenty years, with similar changes across all age groups (Nielsen et al. 2002). The consequences of these marked changes of eating behaviour may be particularly dramatic for children, because food preferences and especially intake patterns develop early in life and show long-term tracking (Kelder et al. 1994; Lauer et al. 1997; Dietz, 1998; Spruijt-Metz et al. 2002). Thus, major changes in food habits and in the culture of eating acquired in childhood may have important long-term health and economic consequences.

During the same time period, the portion sizes of prepared foods have increased markedly. Trends in food portion sizes have been assessed from nationally representative data on 63380 individuals aged 2 years and older from the Nationwide Food Consumption Survey (19771978) and the Continuing Survey of Food Intake by Individuals (1989-1991, 1994-1996 and 1998) in the USA (Nielsen \& Popkin, 2003). For each survey year, the average portion size consumed of specific food items (salty snacks, desserts, soft drinks, fruit drinks, French fries, hamburgers, cheeseburgers, pizza, and Mexican food) was assessed by eating location (home, restaurant or fast food). The results indicate that portion sizes vary by food source, with the largest portions consumed at fast-food establishments and the smallest at other restaurants.
Between 1977 and 1996, food portion sizes increased both inside and outside the home for all categories except pizza. The energy intake from salty snacks increased by $389 \mathrm{~kJ}$, soft drinks by $205 \mathrm{~kJ}$, hamburgers by $406 \mathrm{~kJ}$, French fries by $285 \mathrm{~kJ}$, and Mexican food by $557 \mathrm{~kJ}$ in only two decades (Fig. 3).

Such changes in portion size will affect total energy intake in children. Orlet Fisher et al. (2003) evaluated energy intake, bite size and comments about portion size in thirty children at two series of lunches in which either an age-appropriate portion or a large portion of an entree was served. Doubling an age-appropriate portion of an entree increased entree and total energy intakes at lunch by $25 \%$ and $15 \%$, respectively. Changes were attributable to increases in the average size of the children's bites of the entree without compensatory decreases in the intake of other foods served at the meal. These increases were seen even though observational data indicated that the children were largely unaware of changes in portion size. Greater responsiveness to portion size was associated with higher levels of overeating. Large food portions may constitute an 'obesigenic' environmental influence for children. Therefore, the marketing of foods with appropriate portion sizes may contribute significantly to appropriately meeting the current nutritional needs of children and adolescents.

\section{Conclusions}

Meeting the nutritional needs of children and adolescents is of utmost importance to support their growth and development, and their short- and long-term health, wellbeing and performance. Thus, to meet the nutritional needs of the young generations is of very high priority for societies at large. Current reference values for nutrient intakes vary widely in different parts of Europe, partly due to severe limitations in the available scientific knowledge on nutrient requirements, and partly due to major differences in underlying concepts, definitions and terminology. The available data on dietary intakes and nutritional status in populations of children and adolescents in Europe allow only limited conclusions, primarily because of a lack of consensus on methodological approaches used. Steps towards achieving harmonisation are urgently needed

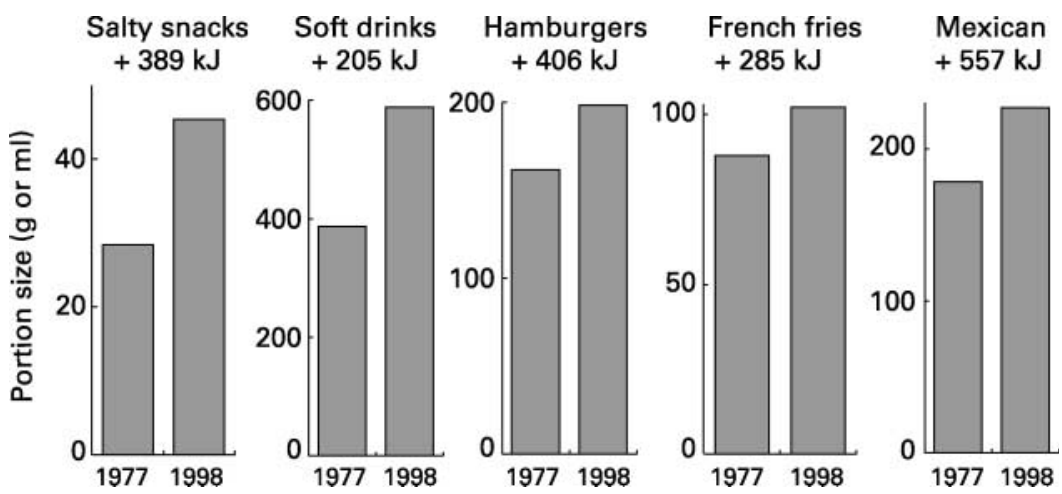

Fig. 3. Trends in food portion sizes from specific food items, assessed by eating location (home, restaurant or fast food), from nationally representative data on 63380 individuals aged 2 years and older between 1977 and 1998 in the USA. Between 1977 and 1996 , food portion sizes increased markedly both inside and outside the home for all categories except pizza. (From Nielsen \& Popkin, 2003.) 
at a time when Western, Central and Eastern European nations rapidly grow more closely together. Dietary studies of food and nutrient intakes across Europe using agreed and validated methodology would be of great value. A concerted action of scientists, scientific societies and governmental agencies from all parts of Europe is required to move towards a consensus on concepts and approaches, definitions, age groups and other technicalities. Such an initiative might be of tremendous value in achieving a stepwise harmonisation of nutrient recommendations as well as data on diets and nutritional status.

Major efforts are also needed to address the health risks arising from not meeting the nutritional needs of a large number of European children at present. In particular, the epidemic increase in the prevalence and severity of childhood obesity at a young age requires urgent attention. Not only the observed trend to a decrease of regular physical activity, but also major changes in food habits, eating behaviour, and the types and amounts of foods consumed are of major concern. Constructive collaboration between academia, health professionals, governmental and public health agencies, and industry is needed to combat this major threat for the health, productivity and overall wellbeing of the European population.

\section{Acknowledgements}

This work was supported by a grant from the Nutritional Needs of Children Task Force of the European branch of the International Life Sciences Institute (ILSI Europe). Industrial members of this task force are Barilla, Coca-Cola, Danone Vitapole, Friesland Coberco, Masterfoods, Nestlé and Numico. Further information about ILSI Europe can be obtained from +32(0)2 7710014 or info@ilsieurope.be. The opinions expressed herein are those of the authors and do not necessarily represent the views of ILSI and ILSI Europe.

\section{References}

Aggett PJ (2004) Functional effects of food: what do we know in children? Br J Nutr 92, Suppl. 2, S223-S226.

Aggett P, Bresson J, Haschke F, et al. (1997) Recommended Dietary Allowances (RDAs), Recommended Dietary Intakes (RDIs), Recommended Nutrient Intakes (RNIs), and Population Reference Intakes (PRIs) are not 'recommended intakes'. ESPGHAN Committee on Nutrition. J Pediatr Gastroenterol Nutr 25, 236-241.

Aggett P, Agostoni C, Axelsson I, et al. (2003) Non-digestible carbohydrates in the diets of infants and young children. ESPGHAN Committee on Nutrition. J Pediatr Gastroenterol Nutr 36, 329-337.

Dietz WH (1998) Childhood weight affects adult morbidity and mortality. J Nutr 128, Suppl. 2, 411S-414S.

Ebbeling CB, Pawlak DB \& Ludwig DS (2002) Childhood obesity: public-health crisis, common sense cure. Lancet $\mathbf{1 0}$, 473-482.

German Nutrition Society, Austrian Nutrition Society, Swiss Society for Nutrition Research, Swiss Nutrition Association (2003) Reference Values for Nutrient Intake. Frankfurt am Main: Umschau Braus.

Institute of Medicine (2003) Dietary Reference Intakes for
Energy, Carbohydrate, Fiber, Fat, Fatty Acids, Cholesterol, Protein, and Amino Acids. Washington, DC: National Academies Press.

Joint World Health Organization/Food and Agriculture Organization Expert Consultation (2003) Diet, Nutrition and the Prevention of Chronic Diseases, WHO Technical Report Series no. 916. Geneva: WHO.

Kalies H, Koletzko B \& von Kries R (2001) Übergewicht bei Vorschulkindern. Der Einfluß von Fernseh- und Computerspiel-Gewohnheiten. Kinderärztliche Praxis 4, 227-234.

Kalies H, Lenz J \& von Kries R (2002) Prevalence of overweight and obesity and trends in body mass index in German preschool children, 1982-1997. Int J Obes Relat Metab Disord 26, $1211-1217$.

Kelder SH, Perry CL, Klepp KI \& Lytle LL (1994) Longitudinal tracking of adolescent smoking, physical activity, and food choice behaviors. Am J Public Health 84, 1121-1126.

Koletzko B, Aggett PJ, Bindels JG, Bung P, Ferre P, Gil A, Lentze MJ, Roberfroid M \& Strobel S (1998) Growth, development and differentiation: a functional food science approach. Br J Nutr 80, Suppl. 1, S5-S45.

Koletzko B, Girardet JP, Klish W \& Tabacco O (2002) Obesity in children and adolescents worldwide: current views and future directions. J Pediatr Gastroenterol Nutr 35, S205-S212.

Lambert J, Agostoni C, Elmadfa I, Hulshof KFAM, Krause E, Livingstone B, Socha P, Pannemans D \& Samartín S (2004) Dietary intake and nutritional status of children and adolescents in Europe. ILSI Europe Nutritional Needs of Children Task Force - Expert Group 2. Br J Nutr 92, Suppl. 00, S000-S000.

Lauer RM, Clarke WR \& Burns TL (1997) Obesity in childhood: the Muscatine Study. Zhonghua Min Guo Xiao Er Ke Yi Xue Hui Za Zhi 38, 432-437.

Nielsen SJ \& Popkin BM (2003) Patterns and trends in food portion sizes, 1977-1998. J Am Med Assoc 289, 450-453.

Nielsen SJ, Siega-Riz AM \& Popkin BM (2002) Trends in energy intake in US between 1977 and 1996: similar shifts seen across age groups. Obes Res 10, 370-378.

Nygard O, Nordrehaug JE, Refsum H, Ueland PM, Farstad M \& Vollset SE (1997) Plasma homocysteine levels and mortality in patients with coronary artery disease. $N$ Engl J Med 337, 230-236.

O'Rahilly S, Farooqi IS, Yeo GS \& Challis BG (2003) Minireview: human obesity - lessons from monogenic disorders. Endocrinology 144, 3757-3764.

Orlet Fisher J, Rolls BJ \& Birch LL (2003) Children's bite size and intake of an entree are greater with large portions than with age-appropriate or self-selected portions. Am J Clin Nutr 77, 1164-1170.

Pencharz P \& Ball RO (2003) How to assess amino acid requirements. In Genetic Expression and Nutrition, pp. 37-50 [C Bachmann and B Koletzko, editors]. Philadelphia, PA: Lippincott Williams \& Wilkins.

Prentice A, Branca F, Decsi T, Fleischer Michaelsen K, Fletcher RJ, Guesry P, Manz F, Vidailhet M, Pannemans D \& Samartín S (2004) Energy and nutrient dietary reference values for children in Europe: methodological approaches and current nutritional recommendations. ILSI Europe Nutritional Needs of Children Task Force - Expert Group 1. Br J Nutr 92, Suppl. 2, S83-S145.

Rauh M, Verwied S, Knerr I, Dörr HG, Sönichsen A \& Koletzko B (2001) Homocysteine concentrations in a German cohort of 500 individuals: reference ranges and determinants of plasma levels in healthy children and their parents. Amino Acids 20, 409-418.

Rimm EB, Willett WC, Hu FB, Sampson L, Colditz GA, Manson JE, Henneskens C \& Stampfer MJ (1998) Folate and 
vitamin $\mathrm{B}_{6}$ from diet and supplements in relation to risk of coronary heart disease among women. J Am Med Assoc 279, 359-364.

Scientific Committee on Food (1993) Nutrient and energy intakes for the European Community (opinion expressed on 11 December 1992). Reports of the Scientific Committee for Food (Thirty-first series), pp. 1-248. Luxembourg: Office for Official Publications of the European Communities. http:// europa.eu.int/comm/food/fs/sc/scf/out89.pdf

Scientific Committee on Food (2003a) Minutes' statement of the Scientific Committee on Food addressing the limitations of extrapolating tolerable upper intake levels of nutrients for children (expressed on 4 April). SCF/CS/NUT/IF/65 Final. Annex XIV, Minutes of the 137th Plenary Meeting of the Scientific Committee on Food held on 2-4 April 2003 in
Brussels. SCF/CS/PLEN/MINS 137 (14 May). http://www. europa.eu.int/comm/food/fs/sc/scf/out198_en.pdf

Scientific Committee on Food (2003b) Opinion of the Scientific Committee on Food on the revision of reference values for nutrition labelling (expressed on 5 March). SCF/CS/NUT/ GEN/18 Final (6 March). http://www.europa.eu.int/comm/ food/fs/sc/scf/out171_en.pdf

Spruijt-Metz D, Lindquist $\mathrm{CH}$, Birch LL, Fisher JO \& Goran MI (2002) Relation between mothers' child-feeding practices and children's adiposity. Am J Clin Nutr 75, 581-586, Published erratum appears in Am J Clin Nutr (2002) 75, 1125.

von Kries R, Koletzko B, Sauerwald T, von Mutius E, Barnert D, Grunert V \& von Voss H (1999) Breastfeeding and obesity: cross sectional study. Br Med J 319, 147-150. 